\title{
Lower fiducial limit of urinary metabolite level as an index of excessive exposure to industrial chemicals
}

\author{
TOSHIKO IMAMURA and MASAYUKI IKEDA \\ Department of Public Health, Kyoto University Faculty of Medicine, Kyoto, Japan
}

\begin{abstract}
Imamura, T., and Ikeda, M. (1973). British Journal of Industrial Medicine, 30, 289-292. Lower fiducial limit of urinary metabolite level as an index of excessive exposure to industrial chemicals. Utilization of the lower fiducial limit $(P=0 \cdot 10)$, rather than the mean, as an index of excessive exposure to industrial chemicals is discussed. Cases of exposure to trichloroethylene, phenol, and toluene are used to illustrate this approach.
\end{abstract}

Since the early studies by Elkins (1954 and 1959), increasing attention has been paid to the quantitative relationship between intensity of exposure of humans to an industrial toxic agent and the level of the agent (or a metabolite derived therefrom) in an appropriate biological sample, and the concept of 'biological threshold limit' has been proposed (Elkins, 1967).

One of the main points to be discussed herein is determination of a screening level for the concentration of the metabolite in the biological specimen so that the factory worker may be protected from excessive exposure above the (atmospheric) threshold limit value (TLV). A proposal is made and substantiated as to utilization of the lower fiducial limit, rather than the mean, as a screening level. Examples of practical procedures are outlined.

\section{Materials and methods}

Previously reported data on the quantitative relationship between the levels of three industrial agents in the air of workrooms and the concentration of corresponding metabolites in the urine of workers exposed have been utilized, namely, toluene exposure $v$ hippuric acid excretion (Ikeda and Ohtsuji, 1969a), environmental phenol $v$ urinary total (free + conjugated) phenols (Ohtsuji and Ikeda, 1972), and trichloroethylene in air $v$ total trichloro-compounds in urine (Ikeda, Ohtsuji,
Imamura, and Komoike, 1972). The normal, i.e., non-exposed values were also reported (Ikeda and Ohtsuji, 1969b). The surveys in these studies were carried out in spring and autumn. Spot urine samples were collected from male workers at around 3 p.m. In some instances the metabolite concentration was corrected for either specific gravity of urine of 1.016 (Buchwald, 1964) or creatinine concentration (Jackson, 1966). The means and the fiducial limits of variations were calculated on the assumption that a log-normal distribution is applicable (Heath, 1967). Regression lines were fitted by the least square method.

\section{Results}

Results from the factory surveys have been schematically depicted in Figure 1. The horizontal and vertical axes represent atmospheric concentration of the toxic agent and urinary level of the metabolite, respectively. The mean metabolite level increases as a linear function of the vapour concentration with an expanding range of variation. Intercepts of the vertical axis by the lines for fiducial ranges give the upper and lower limits of the normal value. The mean and fiducial ranges of the urinary metabolite levels corresponding to the (atmospheric) TLV can be obtained at the intersection of the vertical line passing through the TLV on the horizontal axis and the respective regression lines of means and the fiducial ranges. 


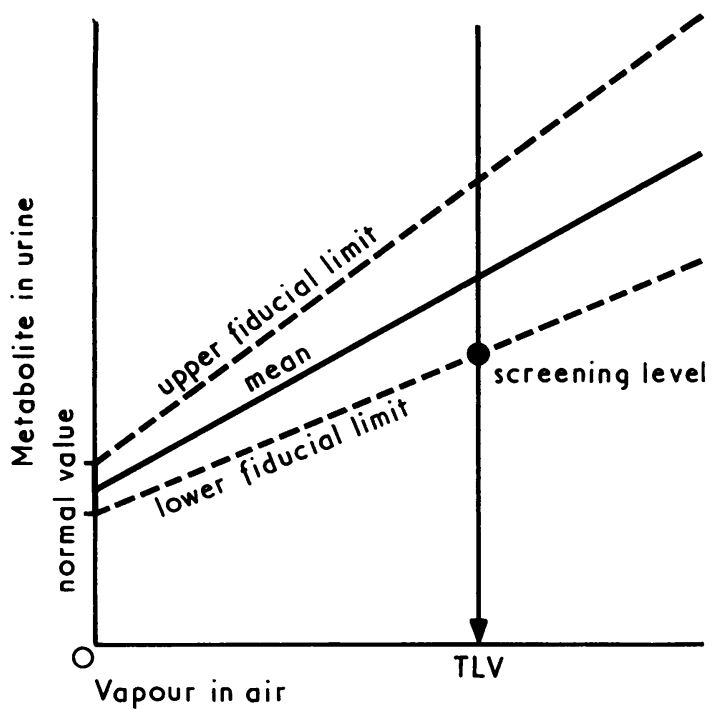

FIG. 1. See text.

The lower fiducial limit, indicated by the solid circle in Fig. 1, gives the screening level at the specified probability. An analysis of the biological specimen may clearly (for example, $P<0 \cdot 10$ ) distinguish the worker exposed to the agent at the TLV from the non-exposed when the screening level is above the upper limit $(P=0 \cdot 10)$ of the normal value (Fig. 1). It is less reliable in case the screening level is within the range $(P=0 \cdot 10)$ of the normal value (Fig. 2).

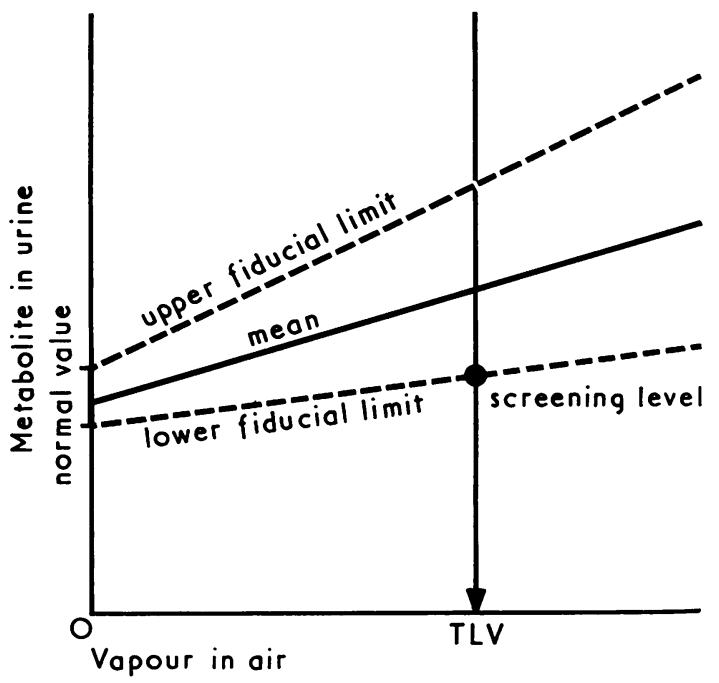

FIG. 2. See text.
Survey data of factories using trichloroethylene, phenol or toluene were rearranged in accordance with this procedure, and the results are summarized in the Table. The probability of 0.10 is selected for the fiducial limit of the exposed value, so that $5 \%$ of the workers exposed to the TLV value of the compound will have metabolite concentrations below the lower fiducial limit. The screening level of total trichloro-compounds after trichloroethylene exposure at the TLV is more than 100 times higher than the maximum of the normal values, indicating that workers exposed at the TLV can be clearly separated from those non-exposed. This applies also to the subjects exposed to phenol vapour at the TLV. Urinary total phenols were measured, with the rate of the lower limit $(P=0 \cdot 10)$ of the exposed value over the upper normal limit $(P=0 \cdot 10)$ being approximately 5 . In the case of toluene exposure, the upper normal limit is approximately $1 \mathrm{~g} /$ litre of urine or $1 \mathrm{~g} / \mathrm{g}$ creatinine while the lower fiducial limit of the TLV-exposed value is between 1 and 2 , indicating that separation of the exposed from the nonexposed can hardly be done regarding urinalysis for hippuric acid. It is clear from the comparison of the three cases in the Table that the reliability of the screening level depends on the ratio between the normal value and the TLV-exposed value as well as on the ranges of variation of the two values.

\section{Discussion}

The screening level may be determined (1) from the relation between the signs and symptoms of the factory workers exposed to the toxic agent and the level of the agent (or a metabolite(s) derived therefrom) in biological specimens (Ahlmark and Forssman, 1951) as in the (atmospheric) TLV, or (2) as the level of the agent (or a metabolite(s)) in the biological specimens obtained from the factory workers exposed to the agent at the TLV. The significance of the excretion rate in relation to the body burden after repeated exposures was recently discussed by Roach (1966), who suggested the advantage of factory surveys and limitation of experimental exposure as a simulation study especially when an agent with a slow excretion rate is to be examined. The biological half-life values of the three agents under study have been reported (Ikeda and Imamura, 1972; Sherwood, 1972). A number of studies, based on the second principle described above, were performed on the factory workers to determine screening levels in relation to the index of excessive exposure to organic solvent vapours (Walkley, Pagnotto, and Elkins, 1961; Ogata, Sugiyama, and Moriyasu, 1962; Rainsford and Lloyd Davies, 1965; Van Haaften and Sie, 1965; Pagnotto and Lieberman, 1967; Docter and Zielhuis, 1967). Most of the publications, however, 


\section{TABLE}

Metabolite Concentration in Urine after Exposure to Trichloroethylene, Phenol, and TOLUENE

\begin{tabular}{|c|c|c|c|c|c|c|}
\hline \multirow{3}{*}{$\begin{array}{c}\text { Chemicals } \\
\text { exposed at } \\
\text { TLV }\end{array}$} & \multirow{3}{*}{$\begin{array}{c}\text { Urinary } \\
\text { metabolites } \\
\text { measured }\end{array}$} & \multirow{3}{*}{$\begin{array}{c}\text { Correction } \\
\text { for urine } \\
\text { concentration }\end{array}$} & \multicolumn{4}{|c|}{ Urinary metabolite levels } \\
\hline & & & \multicolumn{2}{|c|}{ Normal values? } & \multicolumn{2}{|c|}{ Values for exposure at $T L V$} \\
\hline & & & Means & (fiducial ranges $^{8}$ ) & Means & (fiducial ranges ${ }^{8}$ ) \\
\hline $\begin{array}{l}\text { Trichloroethylene } \\
\left(50 \mathrm{ppm}^{1}\right)\end{array}$ & $\begin{array}{l}\text { Total trichloro- } \\
\text { compounds }\end{array}$ & $\begin{array}{l}\text { OV }(\mathrm{mg} / \mathrm{l}) \\
\text { Sp.gr. (mg/1) } \\
\text { Creat. (mg/g) }\end{array}$ & $0-0.9^{9}$ & & $\begin{array}{l}421 \cdot 0 \\
236 \cdot 7 \\
265 \cdot 3\end{array}$ & $\begin{array}{l}(291 \cdot 7-607 \cdot 7) \\
(167 \cdot 7-334 \cdot 6) \\
(148 \cdot 5-473 \cdot 9)\end{array}$ \\
\hline Phenol (5 ppm²) & Total phenols ${ }^{5}$ & $\begin{array}{l}\text { OV }(\mathrm{mg} / 1) \\
\text { Sp.gr. (mg/1) } \\
\text { Creat. (mg/g) }\end{array}$ & $\begin{array}{l}26 \cdot 1 \\
23 \cdot 3 \\
18 \cdot 9\end{array}$ & $\begin{array}{l}(10 \cdot 1-66 \cdot 9) \\
(9 \cdot 0-60 \cdot 4) \\
(7 \cdot 3-49 \cdot 0)\end{array}$ & $\begin{array}{l}608 \cdot 9 \\
448 \cdot 0 \\
394 \cdot 0\end{array}$ & $\begin{array}{l}(358 \cdot 8-1003 \cdot 2) \\
(278 \cdot 6-720 \cdot 6) \\
(258 \cdot 9-599 \cdot 7)\end{array}$ \\
\hline Toluene $\left(100 \mathrm{ppm}^{3}\right)$ & Hippuric acid & $\begin{array}{l}\text { OV }(g / 1) \\
\text { Sp.gr. }(g / 1) \\
\text { Creat. }(g / g)\end{array}$ & $\begin{array}{l}0 \cdot 30 \\
0 \cdot 29 \\
0 \cdot 23\end{array}$ & $\begin{array}{l}(0.09-0.97) \\
(0.08-1.05) \\
(0.06-0.88)\end{array}$ & $\begin{array}{l}3 \cdot 18 \\
2 \cdot 03 \\
2 \cdot 35\end{array}$ & 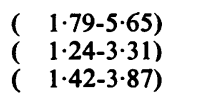 \\
\hline
\end{tabular}

${ }^{1}$ TLV, 1972, of Japanese Association of Industrial Health; MAK, 1971, of Deutsche Forschungsgemeinschaft

'TLV, 1971, of American Conference of Governmental Industrial Hygienists; MAK, 1971, of Deutsche Forschungsgemeinschaft ${ }^{3} \mathrm{TLV}, 1972$, of Japanese Association of Industrial Health; the intended value for TLV, 1971, of American Conference of Governmental Industrial Hygienists

"Trichloroacetic acid plus trichloroethanol

${ }^{5}$ Free plus conjugated phenols

-OV = observed value

Sp.gr. = corrected for a specific gravity of urine of 1.016 (Buchwald, 1964)

Creat. $=$ observed value divided by creatinine concentration (Jackson, 1966)

${ }^{2}$ Recalculated from data previously published (Ikeda and Ohtsuji, 1969b)

'Upper and lower limits; $P=\mathbf{0} \cdot 10$

'Minimum and maximum values observed

dealt with the mean concentration of the metabolites of the compounds under study and less attention was paid to variation in the metabolite concentration at the given atmospheric concentration of the toxic agent. When the screening level is set at the mean of the metabolite concentration corresponding to the TLV, the actual exposure of about half the workers will be underestimated and this is hardly protective of the health of workers. The use of the lower fiducial limit $(P=0 \cdot 10)$ as the screening level will result in under-estimation of the exposure intensity at $5 \%$. The degree of risk of error permitted may vary depending on the purpose of the screening test ; Ellis (1966), for example, took a $90 \%$ confidence limit for the control of lead exposure by means of urinalysis, as in statistical analysis of biological observations in which a $5 \%$ or $10 \%$ risk is usually taken. It is of practical importance to make clear the percentage risk of misjudgement in establishing the screening level. Repeated and periodic follow-up examinations of the exposed workers combined with a control chart technique (Ellis, 1966) should improve the reliability of the urinalysis as a screening test for excessive exposure.

Thanks are due to Professor M. Nishio (Kyoto University Faculty of Medicine) for his interest in this work, and to
M. Ohara for assistance in the preparation of the manuscript.

\section{References}

Ahlmark, A., and Forssman, S. (1951). Evaluating trichloroethylene exposures by urinalyses for trichloroacetic acid, Archives of Industrial Hygiene and Occupational Medici ne 3, 386-398.

Buchwald, H. (1964). The expression of urine analysis results -observations on the use of a specific gravity correction. Annals of Occupational Hygiene, 7, 125-136.

Docter, H. J., and Zielhuis, R. L. (1967). Phenol excretion as a measure of benzene exposure. Annals of Occupational Hygiene, 10, 317-326.

Elkins, H. B. (1954). Analyses of biological materials as indices of exposure to organic solvents. Archives of Industrial Hygiene and Occupational Medicine, 9, 212-222. (1959). The Chemistry of Industrial Toxicology, 2nd ed., pp. 256-257. Wiley, New York.

(1967). Excretory and biologic threshold limits. American Industrial Hygiene Association Journal, 28, 305-314.

Ellis, R. W. (1966). Urinary screening tests to detect excessive lead absorption. British Journal of Industrial Medicine, 23, 263-281.

Heath, D. F. (1967). Normal or log-normal: appropriate distributions. Nature, 213, 1159-1160.

Ikeda, M., and Imamura, T. (1972). Significance of biological half-life as a screening test. Presented at the 17th International Conference on Occupational Health, Buenos Aires, Argentina, September 17-23. 
, and Ohtsuji, H. (1969a). Significance of urinary hippuric acid determination as an index of toluene exposure. British Journal of Industrial Medicine, 26, 244-246.

—, and Ohtsuji, H. (1969b). Hippuric acid, phenol, and trichloroacetic acid levels in the urine of Japanese subjects with no known exposure to organic solvents. British Journal of Industrial Medicine, 26, 162-164.

-, - - Imamura, T., and Komoike, Y. (1972). Urinary excretion of total trichloro-compounds, trichloroethanol, and trichloroacetic acid as a measure of exposure to trichloroethylene and tetrachloroethylene. British Journal of Industrial Medicine, 29, 328-333.

Jackson, S. (1966). Creatinine in urine as an index of urinary excretion rate. Health Physics, 12, 843-850.

Ogata, M., Sugiyama, K., and Moriyasu, H. (1962). Studies on poisoning (IV). Toluene concentration in air and urinary hippuric acid measured by paper-chromatography and mass screening examination method. Acta Medicinae Okayama, 16, 283-292.

Ohtsuji, H., and Ikeda, M. (1972). Quantitative relationship between atmospheric phenol vapour and phenol in the urine of workers in Bakelite factories. British Journal of Industrial Medicine, 29, 70-73.
Pagnotto, L. D., and Lieberman, L. M. (1967). Urinary hippuric acid excretion as an index of toluene exposure. American Industrial Hygiene Association Journal, 28, 129-134.

Rainsford, S. G., and Lloyd Davies, T. A. (1965). Urinary excretion of phenol by men exposed to vapour of benzene: A screening test. British Journal of Industrial Medicine, 22, 21-26.

Roach, S. A. (1966). A more rational basis for air sampling programs. American Industrial Hygiene Association Journal, 27, 1-12.

Sherwood, R. J. (1972). Criteria for occupational exposure to benzene. Presented at the 17th International Conference on Occupational Health, Buenos Aires, Argentina, September 17-23.

Van Haaften, A. B., and Sie, S. T. (1965). The measurement of phenol in urine by gas chromatography as a check on benzene exposure. American Industrial Hygiene Association Journal, 26, 52-58.

Walkley, J. E., Pagnotto, L. D., and Elkins, H. B. (1961). The measurement of phenol in urine as an index of benzene exposure. American Industrial Hygiene Association Journal, 22, 362-367.

Received for publication November 7, 1972. 